\title{
Cytomegalovirus Screening in Pregnancy: A Cost-Effectiveness and Threshold Analysis
}

\author{
Catherine M. Albright, MD ${ }^{1}$ Erika F. Werner, MD² \\ ${ }^{1}$ Division of Maternal-Fetal Medicine, Department of Obstetrics and \\ Gynecology, University of Washington, Seattle, Washington \\ 2 Division of Maternal-Fetal Medicine, Department of Obstetrics and \\ Gynecology, Women and Infants Hospital, The Warren Alpert \\ Medical School of Brown University, Providence, Rhode Island \\ ${ }^{3}$ Division of Maternal-Fetal Medicine, Department of Obstetrics and \\ Gynecology, Duke University, Durham, North Carolina
}

Am J Perinatol 2019;36:678-687.
Brenna L. Hughes, MD³

\begin{abstract}
Address for correspondence Catherine M. Albright, MD, Division of Maternal-Fetal Medicine, Department of Obstetrics and Gynecology, University of Washington, 1959 NE Pacific Street, Box 356460, Seattle, WA 98195-6460 (e-mail: cmalbrig@uw.edu).
\end{abstract}

\author{
Abstract \\ Keywords \\ - cytomegalovirus \\ - cost-effectiveness \\ - pregnancy \\ - hyperimmune \\ globulin \\ - behavioral \\ intervention
}

Objective To determine threshold cytomegalovirus (CMV) infectious rates and treatment effectiveness to make universal prenatal CMV screening cost-effective. Study Design Decision analysis comparing cost-effectiveness of two strategies for the prevention and treatment of congenital CMV: universal prenatal serum screening and routine, risk-based screening. The base case assumptions were a probability of primary CMV of $1 \%$ in seronegative women, hyperimmune globulin (HIG) effectiveness of $0 \%$, and behavioral intervention effectiveness of $85 \%$. Screen-positive women received monthly HIG and screen-negative women received behavioral counseling to decrease CMV seroconversion. The primary outcome was the cost per maternal qualityadjusted life year (QALY) gained with a willingness to pay of $\$ 100,000$ per QALY.

Results In the base case, universal screening is cost-effective, costing $\$ 84,773$ per maternal QALY gained. In sensitivity analyses, universal screening is cost-effective only at a primary CMV incidence of more than $0.89 \%$ and behavioral intervention effectiveness of more than $75 \%$. If HIG is $30 \%$ effective, primary CMV incidence can be $0.82 \%$ for universal screening to be cost-effective.

Conclusion The cost-effectiveness of universal maternal screening for CMV is highly dependent on the incidence of primary CMV in pregnancy. If efficacious, HIG and behavioral counseling allow universal screening to be cost-effective at lower primary CMV rates.
Cytomegalovirus (CMV) is the most common congenital infection affecting between 20 and 40,000 neonates annually. ${ }^{1-3}$ Almost 400 children die and up to 8,000 develop permanent disabilities annually in the United States from this disease, with CMV accounting for 20 to $30 \%$ of cases of congenital hearing loss. A significant proportion of these infections is a result of primary maternal infection during pregnancy, which has been reported to occur at a rate between 1 and $4 \%{ }^{3-6}$ Despite this disease burden, universal screening of pregnant women for CMV is not currently recommended because there is no known effective therapy. 7,8

received

June 28, 2018

accepted after revision

October 30, 2018

published online

December 19, 2018
CMV infection occurs through direct contact with infectious bodily fluids. For women of reproductive age, exposure to urine and saliva of young children is likely the biggest risk factor for transmission. ${ }^{9,10}$ It is possible that maternal CMV infection may be prevented during pregnancy through education and behavioral change because few women are aware of CMV and most regularly, practice behaviors that place them at risk when interacting with young children. ${ }^{11-13}$ Behavioral intervention has been evaluated in several small studies with an effectiveness of up to $85 \%$ in the prevention of primary CMV, $6,11,14,15$ and is a low-risk, potentially high-

Copyright @ 2019 by Thieme Medical Publishers, Inc., 333 Seventh Avenue, New York, NY 10001, USA. Tel: +1(212) 584-4662.
DOI https://doi.org/ 10.1055/s-0038-1676495. ISSN 0735-1631. 
yield intervention that is not routinely discussed by providers. ${ }^{16,17}$ A randomized-controlled trial that evaluated the effects of a brief prenatal behavioral intervention on risk behaviors for maternal CMV found that it was modestly effective in changing behaviors. ${ }^{18}$ This trial did not evaluate incidence of primary CMV in the participants.

Regarding treatment of maternal CMV to prevent congenital infection, hyperimmune globulin (HIG) has unclear efficacy. ${ }^{19,20}$ Nigro et al performed a nonrandomized trial on the use of HIG in women who had a primary CMV infection and had a positive amniocentesis for CMV at less than 21 weeks' gestation or declined an amniocentesis. Those who received HIG had a significantly lower rate of congenitally infected neonates (40 vs. $16 \%, p=0.02$ ). ${ }^{19}$ While promising, this small study was neither randomized nor blinded. Revello et al published a small randomized-controlled trial in which 124 women with primary CMV were randomized to HIG versus placebo. They reported a rate of congenital infection of the fetus (confirmed by amniocentesis) or newborn of $44 \%$ in the placebo group versus $30 \%$ in the HIG group, but this did not reach statistical significance $(p=0.13) .{ }^{20}$ A decision analysis published by Cahill et al in 2009 evaluated the cost-effectiveness of CMV screening and treatment. They found that universal screening for primary maternal CMV is cost-effective when evaluating neonatal quality of life compared with either risk-based screening or screening based on suspicious ultrasound findings. ${ }^{21}$

To our knowledge, there have been no studies which have evaluated both behavioral intervention and HIG in combination for prevention and treatment of maternal CMV and no cost analysis has evaluated CMV screening including both maternal and neonatal quality of life. Therefore, our objectives were to use decision analysis to determine the necessary effectiveness of intravenous HIG as well as targeted behavioral counseling for prevention of congenital CMV, and the threshold incidence of primary CMV that would make universal maternal CMV screening in pregnancy cost-effective.

\section{Materials and Methods}

We developed a decision model to evaluate the costs and benefits of two strategies for prevention and treatment of congenital CMV, universal maternal serum screening, or routine, risk-based screening, in a theoretical cohort of 4 million women pregnant annually in the United States. In the universal screening group, it was assumed that all pregnant women underwent one-time serum screening for CMV prior to 20 weeks of gestation. All women with serologic evidence of primary CMV were treated with monthly HIG to decrease fetal transmission. We assumed that only some seropositive women would undergo amniocentesis and that amniocentesis would occur after 20 weeks of gestation. All seronegative women received a behavioral intervention to reduce their risk of primary CMV in the second and third trimesters. We did not account for the possibility of reinfection in seropositive women because serology is of unclear utility in such cases; as such, we did not model behavioral intervention in seropositive women. Following initial negative serum screening, serum screening could be resent at the discretion of the provider with suspicious ultrasound abnormalities which included intracranial calcifications, microcephaly, hyperechoic bowel, and fetal growth restriction. We did not model routine repeat screening without ultrasound abnormalities. If primary CMV was detected on serum screening or amniocentesis, women were treated with monthly HIG. In the routine care group, serum CMV screening was performed only with suspicious ultrasound abnormalities. Women who then had a positive serum screen for primary CMV were treated with monthly HIG. In both the universal screening and routine care groups, we accounted for the possibility of second and third trimesters primary CMV infection, modified by the effectiveness of behavioral intervention in the screening group. Additionally, in both groups, women may have elected to terminate a pregnancy following a serum screen, ultrasound abnormalities, or amniocentesis consistent with primary CMV, or following an abnormal ultrasound in general. ${ }^{19,22-26}$ Women with primary CMV who elected for termination did not receive monthly HIG. Women in both groups (universal screening and routine care) who screened positive for primary CMV underwent monthly ultrasounds until delivery. Neonates were screened for CMV if either maternal serum screening or amniocentesis was positive, or with symptoms concerning for CMV at birth. All neonates with symptomatic CMV were treated with antivirals, and all neonates with long-term disability from CMV received standard pediatric follow-up for CMV. The analysis was performed from a health care perspective to estimate the total expenditures related to CMV screening and treatment.

To obtain base case probability point estimates and confidence intervals, we conducted an English language search of PubMed to identify relevant publications. The Medical Subject Heading (MeSH) search term cytomegalovirus and the MeSH descriptor cost were used initially and then expanded to find the necessary data for the model. The final search terms included: pregnancy, cytomegalovirus, hyperimmune globulin, cytomegalovirus screening, congenital cytomegalovirus, and behavioral intervention. The search was limited to English language articles only but was not limited by publication date or country of origin. All identified documents were examined and those that were relevant were retrieved. Reference lists of retrieved documents were manually reviewed to identify additional publications. Point estimates were determined from published randomized-controlled trials, prospective cohorts, and national vital statistic data when possible. Retrospective cohorts or review studies were used when no other sources of information were available. If there was not one study that was methodologically superior, we calculated base case point estimates as the unweighted mean or median of the available database on their distributions (-Table 1 ). We made the following assumptions regarding probability point estimates and confidence intervals given limited data: (1) fetal infection always resulted in congenital CMV, but the neonate could be symptomatic or asymptomatic; (2) an adverse reaction to HIG led to 1 hospital day (range, $0-2$ days); (3) fetal CMV infection led to a twofold increased risk of an intrauterine fetal demise (IUFD) (range, relative risk [RR] 1.0-2.0); and (4) treatment with HIG had no effect on IUFD or preterm delivery risk (range, RR 0.5-2.0) (- Table 1). 
Table 1 Probability estimates

\begin{tabular}{|c|c|c|c|}
\hline & Base case & Range & References \\
\hline CMV seroprevalence & 0.555 & $0.295-1.0$ & 46,47 \\
\hline Primary maternal CMV infection & 0.01 & $0-0.04$ & $3-6$ \\
\hline \multicolumn{4}{|l|}{ Serum CMV screening } \\
\hline Sensitivity & 0.143 & $0.05-0.3$ & \multirow[t]{2}{*}{$21,48-50$} \\
\hline Specificity & 0.983 & $0.9-0.99$ & \\
\hline \multicolumn{4}{|l|}{ Amniocentesis } \\
\hline Sensitivity & 0.70 & $0.50-0.99$ & \multirow[t]{2}{*}{$51-55$} \\
\hline Specificity & 1.00 & $0.95-1.00$ & \\
\hline \multicolumn{4}{|l|}{ Efficacy of interventions } \\
\hline Reduction in fetal infection with HIG & 0.00 & $0-1.0$ & 19,20 \\
\hline Reduction in maternal seroconversion with behavioral intervention & 0.85 & $0-1.0$ & $6,11,14,15$ \\
\hline \multicolumn{4}{|l|}{ Probability of termination } \\
\hline Positive serum screen & 0.09 & $0-0.12$ & \multirow[t]{4}{*}{$19,23-26,56^{\mathrm{a}}$} \\
\hline Positive amniocentesis & 0.20 & $0-0.26$ & \\
\hline Ultrasound abnormalities, concerning for CMV & 0.01 & $0-0.20$ & \\
\hline Ultrasound abnormalities, general & 0.12 & $0-0.66$ & \\
\hline \multicolumn{4}{|l|}{ Ultrasound abnormalities } \\
\hline Primary CMV & 0.28 & $0.15-0.49$ & \multirow[t]{2}{*}{$19,22,53,57,58$} \\
\hline Concerning for CMV (CMV negative) & 0.03 & $0-0.03$ & \\
\hline \multicolumn{4}{|l|}{ Probability of amniocentesis } \\
\hline CMV serum screen positive & 0.50 & $0.44-0.52$ & \multirow[t]{2}{*}{$19,26,56^{\mathrm{a}}$} \\
\hline Ultrasound abnormalities & 0.10 & $0-0.50$ & \\
\hline Severe reaction to HIG & 0.001 & $0-0.002$ & $19,20,59,60$ \\
\hline Loss after amniocentesis & 0.001 & $0.001-0.005$ & $21,61-64$ \\
\hline Fetal CMV infection without treatment & 0.40 & $0.10-0.70$ & 43,65 \\
\hline Symptomatic CMV following fetal infection & 0.10 & $0.05-0.10$ & $43,44,66-68$ \\
\hline \multicolumn{4}{|l|}{ Severe disability } \\
\hline Asymptomatic CMV at birth & 0.14 & $0-0.15$ & \multirow[t]{3}{*}{$19,20,43,44,66-68$} \\
\hline Symptomatic CMV at birth & 0.90 & $0.50-0.90$ & \\
\hline Preterm delivery & 0.03 & $0.02-0.11$ & \\
\hline Term delivery & 0.02 & $0.01-0.02$ & 36 \\
\hline \multicolumn{4}{|l|}{ Intrauterine fetal demise } \\
\hline Baseline & 0.006 & $0.005-0.012$ & 69 \\
\hline Fetal CMV infection & 0.012 & $0.005-0.035$ & 19,20 \\
\hline \multicolumn{4}{|l|}{ Preterm delivery } \\
\hline Baseline & 0.12 & $0.10-0.12$ & 37 \\
\hline Fetal CMV infection & 0.23 & $0.10-0.36$ & 20,68 \\
\hline \multicolumn{4}{|l|}{ Neonatal death } \\
\hline Preterm delivery & 0.01 & $0.001-0.38$ & $38,70,71$ \\
\hline Term delivery & 0.0007 & $0.0002-0.001$ & $38,70-73$ \\
\hline Neonatal CMV infection & 0.05 & $0.01-0.10$ & $2,19,43,67,68$ \\
\hline
\end{tabular}

Abbreviations: CMV, cytomegalovirus; HIG, hyperimmune globulin.

anternal data. 
We derived utilities from published literature. Utilities are a means of evaluating the relative quality of life as compared with health. We determined six maternal health states and three neonatal health states that would be relevant for this analysis. The maternal health states included health after the following: pregnancy termination (utility $=0.94$, range $0.77-0.99$ ), miscarriage or fetal loss (utility $=0.94$, range $0.66-0.99$ ), intrauterine fetal demise (utility $=0.92$, range $0.6-0.99$ ), neonatal death (utility $=0.92$, range 0.6-0.99), delivery of a severely affected child from CMV or cerebral palsy (utility $=0.5$, range $0.01-0.9$ ), and delivery of a healthy child (utility $=1$ ). Maternal utilities were derived using the standard gamble and time tradeoff methods. ${ }^{27-33}$ The neonatal health states included: normal health (utility $=1$ ), severe disability (utility $=0.48$, range $0.01-0.89$ ), and death (including termination, miscarriage, IUFD, and neonatal death (utility $=0) .{ }^{34,35}$ The neonatal utilities were derived using the Health Utilities Index and author judgment. ${ }^{34,35}$ Severe disability was defined as serious medical conditions that significantly limit working capacity and include cerebral palsy, mental retardation, blindness, deafness, and epilepsy. ${ }^{36}$ We assumed that the average maternal age at delivery was 26 years (the mean age of first birth in the United States) and the average maternal life expectancy was 81 years. ${ }^{37,38}$ A termination or miscarriage was assumed to reduce maternal quality of life for 1 year, an IUFD or neonatal death was assumed to reduce maternal quality of life for 2 years, and a severely affected child was assumed to impact maternal quality of life for the lifespan of the child. For each of these health states, a maternal utility of 0.99 was assigned for the remainder of her life expectancy following the time frame mentioned for each state. We assigned an average life expectancy of 79 years for healthy infants (lower than the average maternal life expectancy because it includes $50 \%$ males, who have a shorter life expectancy), 65 years for infants with cerebral palsy, and 20 years for infants with severe manifestations of $\mathrm{CMV}^{34,35}$ To calculate qualityadjusted life years (QALYs), we assumed a discounting rate of $3 \%$ in the base case (range $0-5 \%$ ) (-Table 2 ). To determine the exact QALY value, the utility value associated with a given state of health was multiplied by the years lived in that state. Discounting assumes that current health is worth more than future health meaning that the utility of each subsequent year is decreased by $3 \%$ in the above QALY calculation.

We derived cost estimates in a similar fashion to the probability estimates, but additionally queried local and national hospital and insurance data (-Table 2 ). We adjusted all costs to reflect 2018 U.S. dollars. The costs accounted for in the model included the cost of maternal CMV testing, maternal follow-up and treatment, maternal delivery, neonatal screening in those whose mothers were CMV screen positive and in those who were symptomatic at birth, neonatal care, which included the cost of antiviral treatment, and the cost of longterm disability. Delivery costs were based on the gestational age at delivery. Long-term care costs included only direct medical expenses, thus productivity losses were not included.

The primary outcome was the cost per maternal QALY gained with a willingness to pay of $\$ 100,000$ per QALY gained. ${ }^{39-41}$ Neonatal QALYs can only be meaningfully calculated when termination does not occur because a termination for any reason leads to a neonatal QALY of 0 . Therefore, we also evaluated the cost per neonatal QALY gained, assuming termination was not performed, again using a willingness to pay of $\$ 100,000$ per QALY. In addition to the base case analysis, we performed one-, two-, and three-way sensitivity analyses. In particular, this allowed for an investigation into how the incidence of primary maternal CMV, the effectiveness of a behavioral intervention, and effectiveness of HIG might interact. Finally, Monte Carlo simulation (a computational algorithm that relies on repeated random sampling of all variables across their confidence intervals based on their distributions) was utilized given the uncertainty of many of the point estimates. In the Monte Carlo simulation, $\beta$ distributions were used for probability and utility estimates, log normal distributions were used for RRs, and gamma distributions were used for cost variables. Given the plausible variation in all of the probabilities and cost estimates included in the model, no variable was excluded from the Monte Carlo analysis. One hundred thousand simulations were run to estimate the percentage of time that universal CMV screening would be cost-effective as compared with routine care.

We performed all analyses using TreeAge Pro 2018 Suite (TreeAge Software, Inc., Williamstown, MA). The study did not involve human subjects and was exempted from Institutional Review Board approval.

\section{Results}

In the base case we assume that HIG is ineffective, primary maternal CMV incidence is $1 \%$ of those previously seronegative $(0.45 \%$ of all pregnancies assuming a CMV seroprevalence of $55.5 \%$ ), and behavioral intervention effectiveness is $85 \%$. Under these assumptions, universal screening is costeffective, costing $\$ 84,773$ per maternal QALY gained. In oneway sensitivity analyses, for universal screening to remain cost-effective, primary CMV incidence needs to be more than $0.89 \%$ and behavioral intervention needs to be more than $75 \%$ effective. If HIG is $30 \%$ effective, universal screening costs $\$ 74,833$ per maternal QALY gained, and incidence of primary CMV must be more than $0.82 \%$.

Using two- and three-way sensitivity analyses, if primary CMV incidence, HIG effectiveness, or behavioral intervention effectiveness individually decreases, the other variables must increase for universal screening to remain cost-effective. Similarly, if primary CMV incidence, HIG effectiveness, or behavioral intervention effectiveness individually increases, the other variables can decrease and universal screening will remain cost-effective (-Fig. 1). For example, at a primary CMV incidence of less than $0.64 \%$, universal screening is not cost-effective at any efficacy of HIG or behavioral intervention. At CMV incidence of $0.8 \%$ and HIG effectiveness of $30 \%$, behavioral intervention would have to be $93 \%$ effective for universal screening to remain costeffective. However, at CMV incidence of 2 and $4 \%$ and HIG effectiveness of $30 \%$, behavioral intervention only needs to be 30 and $11 \%$ effective, respectively. 
682 Cost-Effectiveness of Universal CMV Screening in Pregnancy Albright et al.

Table 2 Cost and QALY estimates

\begin{tabular}{|c|c|c|c|}
\hline \multicolumn{4}{|l|}{ Costs } \\
\hline Variable & Base case, 2018 USD & Range, 2018 USD & References \\
\hline Maternal serum CMV screening & 180 & $32-321$ & $21,74^{\mathrm{a}}$ \\
\hline Amniocentesis + CMV PCR & 1082 & $146-2,771$ & $21,75-77$ \\
\hline Behavioral intervention & 26 & $13-54$ & 77 \\
\hline \multicolumn{4}{|l|}{ Ultrasound } \\
\hline Initial & 120 & $120-601$ & \multirow[t]{2}{*}{$21,76-78$} \\
\hline Follow-up & 76 & $76-272$ & \\
\hline HIG (one dose) & 1,495 & $714-2,782$ & $21,79-81$ \\
\hline Adverse reaction to HIG & 1,604 & $1,204-2,005$ & 82 \\
\hline Termination & 1,417 & $735-2,026$ & $21,75,76,83$ \\
\hline Miscarriage/fetal loss & 1,053 & $554-1,248$ & 75 \\
\hline Intrauterine fetal demise & 5,002 & $732-85,618$ & 84 \\
\hline \multicolumn{4}{|l|}{ Neonatal death } \\
\hline Term & 94,251 & $8,661-101,671$ & \multirow[t]{2}{*}{71} \\
\hline Preterm & 126,758 & $62,376-155,923$ & \\
\hline \multicolumn{4}{|l|}{ Delivery } \\
\hline \multicolumn{3}{|l|}{ Term } & \multirow[t]{6}{*}{71,85} \\
\hline Maternal & 3,513 & $3,424-3,698$ & \\
\hline Neonatal & 2,254 & $1,507-2,735$ & \\
\hline \multicolumn{3}{|l|}{ Preterm } & \\
\hline Maternal & 5,275 & $4,246-13,011$ & \\
\hline Neonatal & 20,153 & $4,116-345,809$ & \\
\hline Neonatal CMV screening & 53 & $11-1,044$ & 42 \\
\hline \multicolumn{4}{|l|}{ Severe disability } \\
\hline CMV & 236,899 & $198,440-287,346$ & \multirow[t]{2}{*}{$86-88$} \\
\hline Cerebral palsy & 305,399 & $189,968-335,909$ & \\
\hline Symptomatic neonatal CMV & 10,598 & $7,949-13,248$ & 89 \\
\hline \multicolumn{4}{|l|}{ QALYs } \\
\hline Neonatal & Base case & Range & References \\
\hline Severe disability from CMV & 7.14 & $0.12-9.60$ & 34,35 \\
\hline Severe disability from cerebral palsy & 13.66 & $0.19-31.20$ & 34,35 \\
\hline Healthy child & 30.11 & $19.58-79.00$ & 34,35 \\
\hline Maternal & Base case & Range & References \\
\hline Termination & 26.45 & $18.21-54.45$ & $28-30,32$ \\
\hline Miscarriage/fetal loss & 26.45 & $18.14-54.45$ & $29,30,32$ \\
\hline Intrauterine fetal demise & 26.37 & $17.72-54.35$ & 31 \\
\hline Neonatal death & 26.37 & $17.72-54.35$ & 31 \\
\hline Care of neonate with severe disability from CMV & 19.21 & $6.23-52.65$ & $27-30,33,35$ \\
\hline Care of neonate with severe disability from cerebral palsy & 13.39 & $0.19-49.50$ & $27-30,33,35$ \\
\hline Care of healthy child & 26.77 & $18.63-55$ & 27,28 \\
\hline
\end{tabular}

Abbreviations: CMV, cytomegalovirus; HIG, hyperimmune globulin; PCR, polymerase chain reaction; QALY, quality adjusted life year; USD, U.S. Dollar. anternal data. 


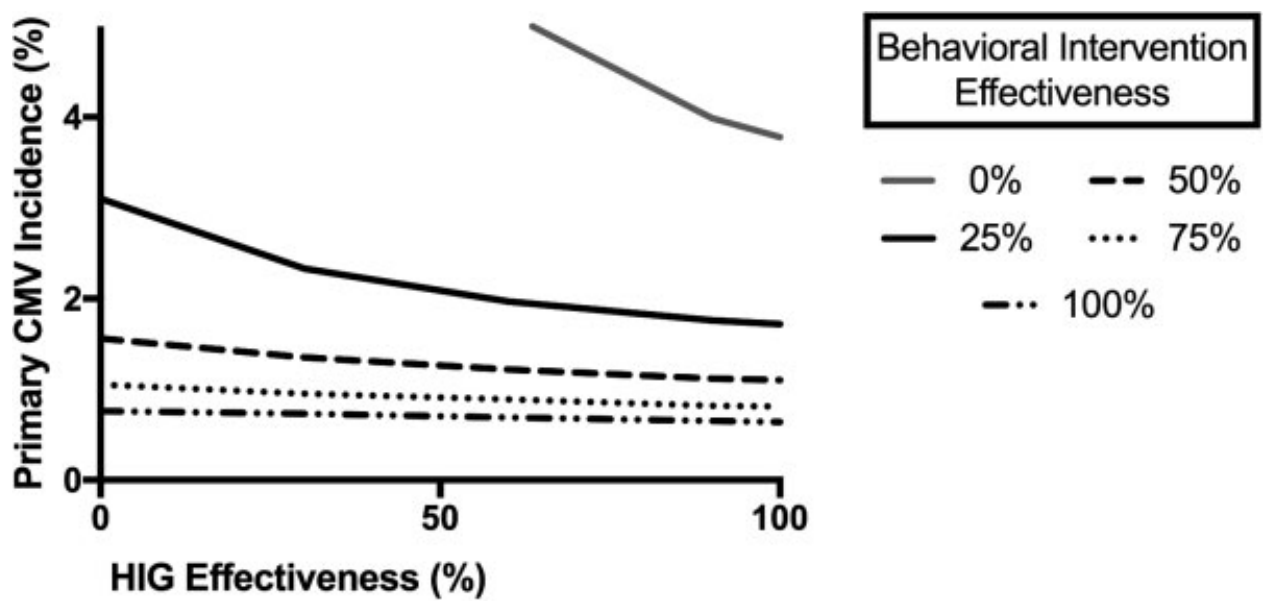

Fig. 1 Cost-effectiveness thresholds at a willingness to pay of $\$ 100,000$ per maternal QALY. CMV, cytomegalovirus; HIG, hyperimmune globulin; QALY, quality-adjusted life year.

Using Monte Carlo simulation, universal screening is costsaving in $21.1 \%$ of simulations and is cost-effective at a threshold of $\$ 100,000$ per maternal QALY in an additional $31.3 \%$ (-Fig. 2). Overall, universal screening is cost-effective or cost-saving in $52.4 \%$ of all possible scenarios.

In the setting in which a woman does not consider termination under any circumstance and HIG is ineffective, universal screening is cost-effective ( $\$ 30,222 /$ neonatal QALY gained). In sensitivity analyses, this model is most sensitive to the rate of primary maternal CMV infection and the decrease in seroconversion following behavioral intervention. In fact, universal screening remains cost-effective if the incidence of primary maternal CMV is $\geq 0.4 \%$ or if behavioral intervention reduces the rate of seroconversion by at least $33 \%$. Additionally, a greater reduction in seroconversion during pregnancy with behavioral intervention allows universal screening to remain cost-effective at lower rates of primary maternal CMV and HIG effectiveness ( - Figs. 3 and 4). Using Monte Carlo simulation, universal screening is cost-saving in $19.7 \%$ of simulations and is cost-effective at a threshold of $\$ 100,000$ per neonatal QALY in an additional $43.1 \%$ (-Fig. 5). Overall, universal screening is cost-effective or cost-saving in $62.8 \%$ of all possible scenarios.

\section{Comment}

In the United States, universal maternal screening for CMV is cost-effective from the maternal standpoint even assuming HIG is ineffective, but only assuming the incidence of primary CMV is more than $0.89 \%$ of those previously seronegative (therefore, $0.4 \%$ of women assuming a CMV seroprevalence of 55.5\%). Behavioral counseling to prevent seroconversion during pregnancy and HIG to prevent and treat congenital $\mathrm{CMV}$, if they are efficacious, allows universal screening to be cost-effective at lower rates of primary CMV infection. From a neonatal perspective, in a cohort in which no woman terminates her pregnancy, universal screening is cost-effective at lower rates of primary CMV.

In this analysis, our base case assumed that HIG was ineffective because the efficacy is unproven at this time and is only recommended within a research study. We did

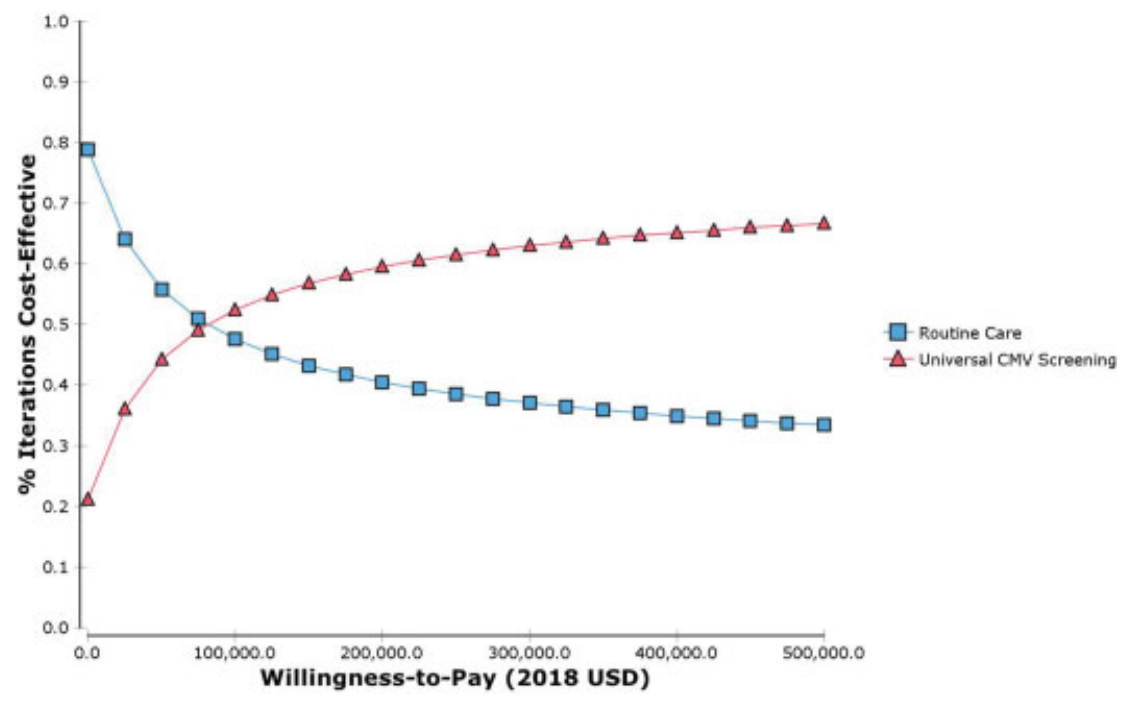

Fig. 2 Acceptability curve for Monte Carlo simulation for maternal quality of life demonstrating willingness to pay based on 100,000 simulations. CMV, cytomegalovirus; USD, U.S. dollars. 


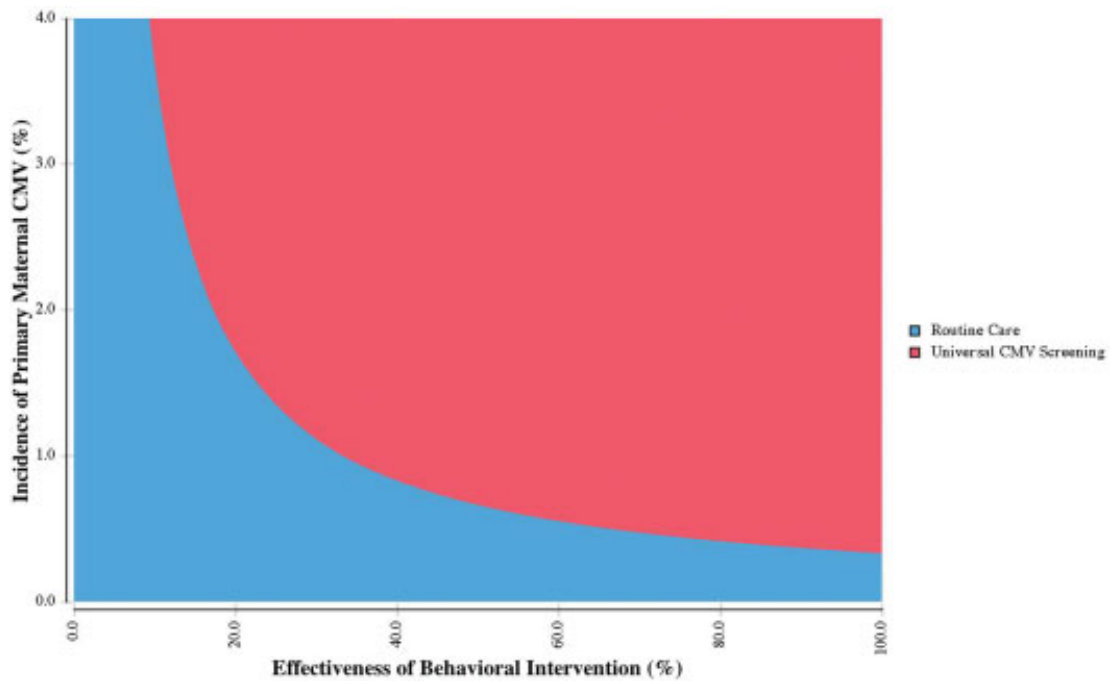

Fig. 3 Two-way sensitivity analysis demonstrating the cost-effectiveness of routine care versus universal screening based on primary CMV incidence and behavioral intervention effectiveness. CMV, cytomegalovirus.

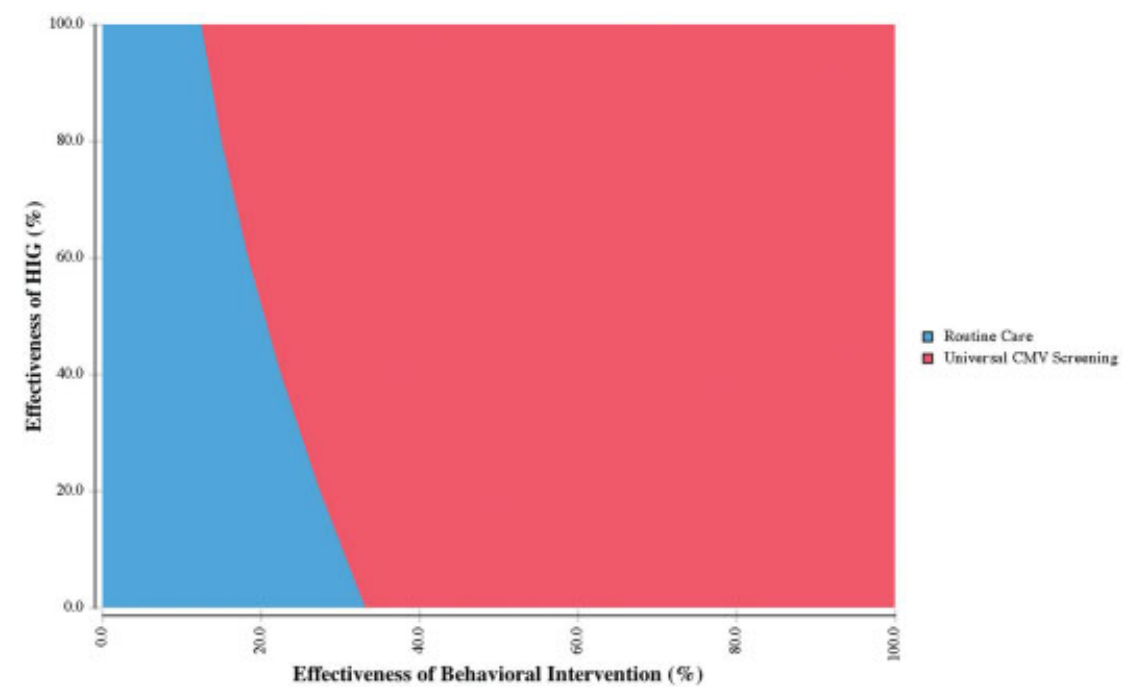

Fig. 4 Two-way sensitivity analysis demonstrating the cost-effectiveness of routine care versus universal screening based on HIG effectiveness and behavioral intervention effectiveness. CMV, cytomegalovirus; HIG, hyperimmune globulin.

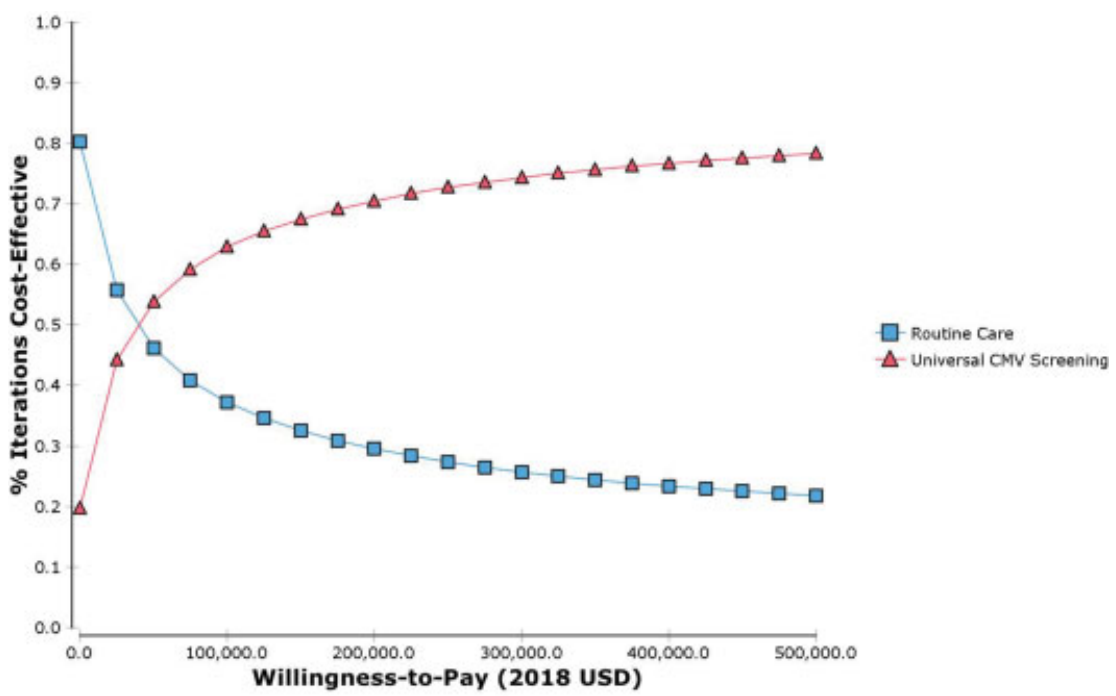

Fig. 5 Acceptability curve for Monte Carlo simulation for neonatal quality of life demonstrating willingness to pay based on 100,000 simulations. CMV, cytomegalovirus; USD, U.S. dollars. 
not account for the risk of reinfection in seropositive women because serology may not be useful for diagnosis and none of the current studies has evaluated the efficacy of HIG in the setting of reinfection. We similarly did not model a behavioral intervention for those women who were CMV screen positive. Additionally, given the lack of data, HIG was assumed to have no effect on IUFD or preterm delivery risk. The study by Revello et al noted a higher absolute risk of prematurity in the HIG arm; however, the finding was not statistically significant and the numbers were small. ${ }^{20}$ Alternatively, it is possible that if HIG proves effective in reducing the risk of fetal transmission and congenital infection, prematurity may be decreased. To account for these possibilities, we varied this parameter in our sensitivity analyses. Studies evaluating the effectiveness of a behavioral intervention are difficult to conduct and many that have been performed have significant design flaws. ${ }^{6,11,14,15}$ To account for this, we evaluated all possibilities for behavioral intervention effectiveness (0-100\%). Regarding neonatal care, we did not model universal neonatal CMV screening because while it may be cost-effective, ${ }^{42}$ it is not currently standard of care. Finally, we only modeled treatment for long-term severe disability from CMV and as such, we did not model the follow-up and treatment for mild to moderate hearing loss caused by congenital CMV.

Strengths of this study are the ability to evaluate large ranges of costs and probabilities. In the setting of limited primary data and uncertainty about the efficacy of the available interventions, including HIG and behavioral intervention, this allows for a critical evaluation of thresholds necessary to make these interventions cost-effective. We created a model that, we believe, will accurately reflect clinical practice, should HIG prove to be efficacious. This includes a behavioral intervention for those women found to be seronegative and multiple doses of HIG in those found to be seropositive. This is in contrast to the prior cost-effectiveness analysis performed by Cahill et $\mathrm{al}^{21}$ which did not consider the impact of a behavioral intervention and also did not take into account multiple doses of HIG. While the data on behavioral intervention for primary maternal CMV prevention is sparse, hygiene education could be easily implemented as part of prenatal care, therefore making it necessary to include in this model. Finally, our outcomes evaluate both maternal and neonatal quality of life.

The major limitation of all cost analyses is that the evaluation is only as good as the available data. The incidence of seroconversion varies widely based on setting-country, urban versus rural, and high versus low income. ${ }^{4}$ We have used conservative estimates based on data from high socioeconomic countries which should reflect the population of the United States. Most importantly, regarding treatment of maternal CMV with HIG to prevent congenital infection, there is unclear evidence of efficacy. ${ }^{19,20}$ Subsequent randomized-controlled trials are ongoing including a randomized-controlled trial evaluating HIG in the treatment of primary maternal CMV (ClinicalTrials.gov, ID number: NCT01376778). This current analysis may help guide policy in the future once this trial is completed and with more accurate data from this trial, our analysis could be reperformed. Another limitation is that outcomes such as a termination or miscarriage lead to a neonatal QALY of 0 . Because of the nature of this specific analysis, we primarily ran the analyses from the maternal point of view, but secondarily ran the analyses from a neonatal standpoint excluding terminations, allowing it to be more generalizable. Finally, we did not account for indirect costs, such as loss of work.

The birth prevalence of congenital CMV in the United States has been reported to be $\sim 0.7 \%,{ }^{43,44}$ with up to $75 \%$ of these as a result of maternal reinfection. ${ }^{45}$ Assuming a fetal transmission rate of $40 \%$ following a primary infection (and much lower, around $1.5 \%$, in the setting of reinfection ${ }^{43}$ ), the overall rate of primary CMV may be closer to $0.7 \%$ in many populations.

Based on the results of this analysis, if the results of the ongoing studies of treatment efficacy of HIG for primary maternal CMV demonstrate an efficacy of $\geq 30 \%$ along with an incidence of primary CMV of more than $0.82 \%$, universal screening may be cost-effective. Even if the ongoing studies do not demonstrate HIG efficacy, universal CMV screening is still cost-effective as long as the incidence of CMV remains above $0.89 \%$. If primary prevention of CMV using behavioral intervention is more effective than expected, universal screening will remain cost-effective at a lower CMV incidence.

Note

This study was presented as a poster at the 2015 Society for Maternal-Fetal Medicine Annual Meeting, February 2-7, 2015, San Diego, CA.

Conflict of Interest

None declared.

\section{References}

1 Cannon MJ. Congenital cytomegalovirus (CMV) epidemiology and awareness. J Clin Virol 2009;46(Suppl 4):S6-S10

2 Boppana SB, Ross SA, Fowler KB. Congenital cytomegalovirus infection: clinical outcome. Clin Infect Dis 2013;57(Suppl 4):S178-S181

3 Britt W. Cytomegalovirus A2. In: Remington JS, Klein JO, Wilson $C B$, Nizet V, Maldonado YA, eds. Infectious Diseases of the Fetus and Newborn, 7th edition. Chap 23. Philadelphia: W.B. Saunders; 2011:706-755

4 Hyde TB, Schmid DS, Cannon MJ. Cytomegalovirus seroconversion rates and risk factors: implications for congenital CMV. Rev Med Virol 2010;20(05):311-326

5 Revello MG, Gerna G. Diagnosis and management of human cytomegalovirus infection in the mother, fetus, and newborn infant. Clin Microbiol Rev 2002;15(04):680-715

6 Revello MG, Tibaldi C, Masuelli G, et al; CCPE Study Group Prevention of primary cytomegalovirus infection in pregnancy. EBioMedicine 2015;2(09):1205-1210

7 American College of Obstetricians and Gynecologists Practice bulletin no. 151: Cytomegalovirus, parvovirus B19, varicella zoster, and toxoplasmosis in pregnancy. Obstet Gynecol 2015; 125(06):1510-1525

8 Hughes BL, Gyamfi-Bannerman C; Society for Maternal-Fetal Medicine (SMFM). Diagnosis and antenatal management of congenital cytomegalovirus infection. Am J Obstet Gynecol 2016;214 (06):B5-B11

9 Revello MG, Campanini G, Piralla A, et al. Molecular epidemiology of primary human cytomegalovirus infection in pregnant women and their families. J Med Virol 2008;80(08):1415-1425 
10 Staras SA, Flanders WD, Dollard SC, Pass RF, McGowan JE Jr, Cannon MJ. Cytomegalovirus seroprevalence and childhood sources of infection: a population-based study among pre-adolescents in the United States. J Clin Virol 2008;43(03):266-271

11 Adler SP, Finney JW, Manganello AM, Best AM. Prevention of child-tomother transmission of cytomegalovirus by changing behaviors: a randomized controlled trial. Pediatr Infect Dis J 1996;15(03):240-246

12 Harvey J, Dennis C-L. Hygiene interventions for prevention of cytomegalovirus infection among childbearing women: systematic review. J Adv Nurs 2008;63(05):440-450

13 Cannon MJ, Westbrook K, Levis D, Schleiss MR, Thackeray R, Pass RF. Awareness of and behaviors related to child-to-mother transmission of cytomegalovirus. Prev Med 2012;54(05):351-357

14 Adler SP, Finney JW, Manganello AM, Best AM. Prevention of childto-mother transmission of cytomegalovirus among pregnant women. J Pediatr 2004;145(04):485-491

15 Vauloup-Fellous C, Picone O, Cordier A-G, et al. Does hygiene counseling have an impact on the rate of CMV primary infection during pregnancy? Results of a 3-year prospective study in a French hospital. J Clin Virol 2009;46(Suppl 4):S49-S53

16 Centers for Disease Control and Prevention (CDC). Knowledge and practices of obstetricians and gynecologists regarding cytomegalovirus infection during pregnancy-United States, 2007. Morb Mortal Wkly Rep 2008;57(03):65-68

17 Korver AM, de Vries JJ, de Jong JW, Dekker FW, Vossen AC, Oudesluys-Murphy AM. Awareness of congenital cytomegalovirus among doctors in the Netherlands. J Clin Virol 2009;46(Suppl 4):S11-S15

18 Hughes BL, Gans KM, Raker C, Hipolito ER, Rouse DJ. A brief prenatal intervention of behavioral change to reduce the risk of maternal cytomegalovirus: a randomized controlled trial. Obstet Gynecol 2017;130(04):726-734

19 Nigro G, Adler SP, La Torre R, Best AM; Congenital Cytomegalovirus Collaborating Group. Passive immunization during pregnancy for congenital cytomegalovirus infection. $\mathrm{N}$ Engl J Med 2005;353(13):1350-1362

20 Revello MG, Lazzarotto T, Guerra B, et al; CHIP Study Group. A randomized trial of hyperimmune globulin to prevent congenital cytomegalovirus. N Engl J Med 2014;370(14):1316-1326

21 Cahill AG, Odibo AO, Stamilio DM, Macones GA. Screening and treating for primary cytomegalovirus infection in pregnancy: where do we stand? A decision-analytic and economic analysis. Am J Obstet Gynecol 2009;201(05):466.e1-466.e7

22 Guerra B, Simonazzi G, Puccetti C, et al. Ultrasound prediction of symptomatic congenital cytomegalovirus infection. Am J Obstet Gynecol 2008;198(04):380.e1-380.e7

23 Pryde PG, Drugan A, Johnson MP, Isada NB, Evans MI. Prenatal diagnosis: choices women make about pursuing testing and acting on abnormal results. Clin Obstet Gynecol 1993;36(03):496-509

24 Revello MG, Fabbri E, Furione M, et al. Role of prenatal diagnosis and counseling in the management of 735 pregnancies complicated by primary human cytomegalovirus infection: a 20 -year experience. J Clin Virol 2011;50(04):303-307

25 Visentin S, Manara R, Milanese L, et al. Early primary cytomegalovirus infection in pregnancy: maternal hyperimmunoglobulin therapy improves outcomes among infants at 1 year of age. Clin Infect Dis 2012;55(04):497-503

26 LeFevre ML, Bain RP, Ewigman BG, Frigoletto FD, Crane JP, McNellis D; RADIUS (Routine Antenatal Diagnostic Imaging with Ultrasound) Study Group. A randomized trial of prenatal ultrasonographic screening: impact on maternal management and outcome. Am J Obstet Gynecol 1993;169(03):483-489

27 Pham CT, Crowther CA. Birth outcomes: utility values that postnatal women, midwives and medical staff express. BJOG 2003;110 (02):121-127

28 Vandenbussche FP, De Jong-Potjer LC, Stiggelbout AM, Le Cessie S, Keirse MJ. Differences in the valuation of birth outcomes among pregnant women, mothers, and obstetricians. Birth 1999;26(03): 178-183
29 Kaimal AJ, Norton ME, Kuppermann M. Prenatal testing in the genomic age: clinical outcomes, quality of life, and costs. Obstet Gynecol 2015;126(04):737-746

30 Kuppermann M, Norton ME, Thao K, et al. Preferences regarding contemporary prenatal genetic tests among women desiring testing: implications for optimal testing strategies. Prenat Diagn 2016;36(05):469-475

31 Kuppermann M, Nease RF, Learman LA, Gates E, Blumberg B, Washington AE. Procedure-related miscarriages and Down syndrome-affected births: implications for prenatal testing based on women's preferences. Obstet Gynecol 2000;96(04):511-516

32 Sonnenberg FA, Burkman RT, Hagerty CG, Speroff L, Speroff T. Costs and net health effects of contraceptive methods. Contraception 2004;69(06):447-459

33 Carroll AE, Downs SM. Improving decision analyses: parent preferences (utility values) for pediatric health outcomes. J Pediatr 2009;155(01):21-25

34 Tengs TO, Wallace A. One thousand health-related quality-of-life estimates. Med Care 2000;38(06):583-637

35 Institute of Medicine (US) Committee to Study Priorities for Vaccine DevelopmentStratton KR, Durch JS, Lawrence RS. Cytomegalovirus. Washington, DC: National Academies Press (US); 2000

36 Moster D, Lie RT, Markestad T. Long-term medical and social consequences of preterm birth. N Engl J Med 2008;359(03): 262-273

37 Hamilton BE, Martin JA, Osterman MJ, Curtin SC, Matthews TJ Births: final data for 2014. Natl Vital Stat Rep 2015;64(12):1-64

38 Kochanek KD, Murphy SL, Xu J, Tejada-Vera B. Deaths: final data for 2014. Natl Vital Stat Rep 2016;65(04):1-122

39 Hirth RA, Chernew ME, Miller E, Fendrick AM, Weissert WG. Willingness to pay for a quality-adjusted life year: in search of a standard. Med Decis Making 2000;20(03):332-342

40 Kaplan RM, Bush JW. Health-related quality of life measurement for evaluation research and policy analysis. Health Psychol 1982;1 (01):61-80

41 Werner EF, Wheeler S, Burd I. Creating decision trees to assess cost-effectiveness in clinical research. J Biom Biostat 2012;S7:004. Doi: 10.4172/2155-6180.S7-004

42 Gantt S, Dionne F, Kozak FK, et al. Cost-effectiveness of universal and targeted newborn screening for congenital cytomegalovirus infection. JAMA Pediatr 2016;170(12):1173-1180

43 Kenneson A, Cannon MJ. Review and meta-analysis of the epidemiology of congenital cytomegalovirus (CMV) infection. Rev Med Virol 2007;17(04):253-276

44 Dollard SC, Grosse SD, Ross DS. New estimates of the prevalence of neurological and sensory sequelae and mortality associated with congenital cytomegalovirus infection. Rev Med Virol 2007;17 (05):355-363

45 Wang C, Zhang X, Bialek S, Cannon MJ. Attribution of congenital cytomegalovirus infection to primary versus non-primary maternal infection. Clin Infect Dis 2011;52(02):e11-e13

46 Bate SL, Dollard SC, Cannon MJ. Cytomegalovirus seroprevalence in the United States: the national health and nutrition examination surveys, 1988-2004. Clin Infect Dis 2010;50(11):1439-1447

47 Cannon MJ, Schmid DS, Hyde TB. Review of cytomegalovirus seroprevalence and demographic characteristics associated with infection. Rev Med Virol 2010;20(04):202-213

48 Lazzarotto T, Spezzacatena P, Varani S, et al. Anticytomegalovirus (anti-CMV) immunoglobulin G avidity in identification of pregnant women at risk of transmitting congenital CMV infection. Clin Diagn Lab Immunol 1999;6(01):127-129

49 Lazzarotto T, Gabrielli L, Lanari M, et al. Congenital cytomegalovirus infection: recent advances in the diagnosis of maternal infection. Hum Immunol 2004;65(05):410-415

50 Macé M, Sissoeff L, Rudent A, Grangeot-Keros L. A serological testing algorithm for the diagnosis of primary CMV infection in pregnant women. Prenat Diagn 2004;24(11):861-863 
51 Goegebuer T, Van Meensel B, Beuselinck K, et al. Clinical predictive value of real-time PCR quantification of human cytomegalovirus DNA in amniotic fluid samples. J Clin Microbiol 2009;47 (03):660-665

52 Liesnard C, Donner C, Brancart F, Gosselin F, Delforge ML, Rodesch F. Prenatal diagnosis of congenital cytomegalovirus infection: prospective study of 237 pregnancies at risk. Obstet Gynecol 2000;95(6 Pt 1) 881-888

53 Azam AZ, Vial Y, Fawer CL, Zufferey J, Hohlfeld P. Prenatal diagnosis of congenital cytomegalovirus infection. Obstet Gynecol 2001;97(03):443-448

54 Enders M, Daiminger A, Exler S, Ertan K, Enders G, Bald R. Prenatal diagnosis of congenital cytomegalovirus infection in 115 cases: a 5 years' single center experience. Prenat Diagn 2017;37(04):389-398

55 Bilavsky E, Pardo J, Attias J, et al. Clinical implications for children born with congenital cytomegalovirus infection following a negative amniocentesis. Clin Infect Dis 2016;63(01):33-38

56 Guerra B, Simonazzi G, Banfi A, et al. Impact of diagnostic and confirmatory tests and prenatal counseling on the rate of pregnancy termination among women with positive cytomegalovirus immunoglobulin M antibody titers. Am J Obstet Gynecol 2007; 196(03):221.e1-221.e6

57 Crane JP, LeFevre ML, Winborn RC, et al; The RADIUS Study Group A randomized trial of prenatal ultrasonographic screening: impact on the detection, management, and outcome of anomalous fetuses. Am J Obstet Gynecol 1994;171(02):392-399

58 Beke A, Latkóczy K, Nagy GR, et al. Comparison of prevalence of toxoplasma and cytomegalovirus infection in cases with fetal ultrasound markers in the second trimester of pregnancy. Prenat Diagn 2011;31(10):945-948

59 Polilli E, Parruti G, D'Arcangelo F, et al. Preliminary evaluation of the safety and efficacy of standard intravenous immunoglobulins in pregnant women with primary cytomegalovirus infection. Clin Vaccine Immunol 2012;19(12):1991-1993

60 Centers for Disease Control and Prevention (CDC) Renal insufficiency and failure associated with immune globulin intravenous therapy-United States, 1985-1998. Morb Mortal Wkly Rep 1999; 48(24):518-521

61 Odibo AO, Gray DL, Dicke JM, Stamilio DM, Macones GA, Crane JP. Revisiting the fetal loss rate after second-trimester genetic amniocentesis: a single center's 16-year experience. Obstet Gynecol 2008;111(03):589-595

62 Eddleman KA, Malone FD, Sullivan L, et al. Pregnancy loss rates after midtrimester amniocentesis. Obstet Gynecol 2006;108(05): 1067-1072

63 Mujezinovic F, Alfirevic Z. Procedure-related complications of amniocentesis and chorionic villous sampling: a systematic review. Obstet Gynecol 2007;110(03):687-694

64 Akolekar R, Beta J, Picciarelli G, Ogilvie C, D’Antonio F. Procedurerelated risk of miscarriage following amniocentesis and chorionic villus sampling: a systematic review and meta-analysis. Ultrasound Obstet Gynecol 2015;45(01):16-26

65 Enders G, Bäder U, Lindemann L, Schalasta G, Daiminger A. Prenatal diagnosis of congenital cytomegalovirus infection in 189 pregnancies with known outcome. Prenat Diagn 2001;21(05):362-377

66 Stagno S, Whitley RJ. Herpesvirus infections of pregnancy. Part I: cytomegalovirus and Epstein-Barr virus infections. N Engl J Med 1985;313(20):1270-1274

67 Stagno S, Pass RF, Cloud G, et al. Primary cytomegalovirus infection in pregnancy. Incidence, transmission to fetus, and clinical outcome. JAMA 1986;256(14):1904-1908

68 Fowler KB, Stagno S, Pass RF, Britt WJ, Boll TJ, Alford CA. The outcome of congenital cytomegalovirus infection in relation to maternal antibody status. N Engl J Med 1992;326(10):663-667

69 Fetal and Perinatal Mortality. United States, 2006. 2012. Available at: http://www.cdc.gov/nchs/data/nvsr/nvsr60/nvsr60_08.pdf. Accessed August 6, 2018
70 Clements KM, Barfield WD, Ayadi MF, Wilber N. Preterm birthassociated cost of early intervention services: an analysis by gestational age. Pediatrics 2007;119(04):e866-e874

71 Phibbs CS, Schmitt SK. Estimates of the cost and length of stay changes that can be attributed to one-week increases in gestational age for premature infants. Early Hum Dev 2006;82(02):85-95

72 McIntire DD, Bloom SL, Casey BM, Leveno KJ. Birth weight in relation to morbidity and mortality among newborn infants. N Engl J Med 1999;340(16):1234-1238

73 Smith GC. Life-table analysis of the risk of perinatal death at term and post term in singleton pregnancies. Am J Obstet Gynecol 2001;184(03):489-496

74 Luan FL, Kommareddi M, Ojo AO. Universal prophylaxis is cost effective in cytomegalovirus serology-positive kidney transplant patients. Transplantation 2011;91(02):237-244

75 Harris RA, Washington AE, Nease RF Jr, Kuppermann M. Cost utility of prenatal diagnosis and the risk-based threshold. Lancet 2004;363(9405)276-282

76 Odibo AO, Stamilio DM, Nelson DB, Sehdev HM, Macones GA. A cost-effectiveness analysis of prenatal screening strategies for Down syndrome. Obstet Gynecol 2005;106(03):562-568

77 Physician Fee Schedule Search.. Available at: https://www.cms. gov/apps/physician-fee-schedule/search/search-criteria.aspx. Accessed August 6, 2018

78 Hawk AF, Chang EY, Shields SM, Simpson KN. Costs and clinical outcomes of noninvasive fetal RhD typing for targeted prophylaxis. Obstet Gynecol 2013;122(03):579-585

79 Duff P. Diagnosis and Management of CMV Infection in Pregnancy. 2010. Available at: http://www.perinatology.com//perinatology/ Volume1-Issue1/Cytomegalovirusprint.htm. Accessed August 6, 2018

80 Jordan S, Cunningham-Rundles C, McEwan R. Utility of intravenous immune globulin in kidney transplantation: efficacy, safety, and cost implications. Am J Transplant 2003;3(06):653-664

81 Drug Result Page - MICROMEDEX®. Available at: http://www. micromedexsolutions.com/micromedex2/librarian/CS/19417E/ ND_PR/evidencexpert/ND_P/evidencexpert/DUPLICATIONSHIELDSYNC/8BB230/ND_PG/evidencexpert/ND_B/evidencexpert/ND_AppProduct/evidencexpert/ND_T/evidencexpert/PFActionId/evidencexpert.GoToDashboard ?docId $=153000 \&$ contentSetId $=100 \&$ title $=$ Cytomegalovirus + Immune + Globulin $\% 2 \mathrm{C}+$ Human $\&$ servicesTitle $=$ Cytomegalovirus + Immune + Globulin $\% 2 \mathrm{C}+$ Human\&brandName $=$ Cytogam\#. Accessed August 6, 2018

82 Bivins HA Jr, McCallum OJ, Roegge DD. The Mother's House: a new concept in antepartum care. Am J Obstet Gynecol 2007;197(02): 201.e1-201.e3

83 Caughey AB, Kuppermann M, Norton ME, Washington AE. Nuchal translucency and first trimester biochemical markers for down syndrome screening: a cost-effectiveness analysis. Am J Obstet Gynecol 2002;187(05):1239-1245

84 Gold KJ, Sen A, Xu X. Hospital costs associated with stillbirth delivery. Matern Child Health J 2013;17(10):1835-1841

85 Gilbert WM, Nesbitt TS, Danielsen B. The cost of prematurity: quantification by gestational age and birth weight. Obstet Gynecol 2003;102(03):488-492

86 Waitzman NJ, Romano PS, Scheffler RM. Estimates of the economic costs of birth defects. Inquiry 1994;31(02):188-205

87 Mohr PE, Feldman JJ, Dunbar JL, et al. The societal costs of severe to profound hearing loss in the United States. Int J Technol Assess Health Care 2000;16(04):1120-1135

88 Keren R, Helfand M, Homer C, McPhillips H, Lieu TA. Projected cost-effectiveness of statewide universal newborn hearing screening. Pediatrics 2002;110(05):855-864

89 Dempsey JC, Sorensen TK, Williams MA, et al. Prospective study of gestational diabetes mellitus risk in relation to maternal recreational physical activity before and during pregnancy. Am J Epidemiol 2004; 159(07):663-670 